\title{
High-Ti-concentration aerogels for bright $x$-ray sources
}

F. Perez, J. R. Patterson, M. May, J. Emig, J. Colvin, M. Biener, A. Wittstock, J. H. Satcher, S. A. Gammon, J. F. Poco, S. Fujioka, Z. Zhang, H. Nishimura, K. B.

Fournier

April 22, 2013 
This document was prepared as an account of work sponsored by an agency of the United States government. Neither the United States government nor Lawrence Livermore National Security, LLC, nor any of their employees makes any warranty, expressed or implied, or assumes any legal liability or responsibility for the accuracy, completeness, or usefulness of any information, apparatus, product, or process disclosed, or represents that its use would not infringe privately owned rights. Reference herein to any specific commercial product, process, or service by trade name, trademark, manufacturer, or otherwise does not necessarily constitute or imply its endorsement, recommendation, or favoring by the United States government or Lawrence Livermore National Security, LLC. The views and opinions of authors expressed herein do not necessarily state or reflect those of the United States government or Lawrence Livermore National Security, LLC, and shall not be used for advertising or product endorsement purposes.

This work performed under the auspices of the U.S. Department of Energy by Lawrence Livermore National Laboratory under Contract DE-AC52-07NA27344. 


\title{
High-Ti-concentration aerogels for bright $x$-ray sources
}

\author{
F. Pérez ${ }^{1}$, J. R. Patterson ${ }^{1}$, M. May ${ }^{1}$, J. Emig ${ }^{1}$, J. Colvin $^{1}$, M. Biener ${ }^{1}$, A. Wittstock ${ }^{1}$, J. H. \\ Satcher, Jr' ${ }^{1}$, S. A. Gammon ${ }^{1}$, J. F. Poco ${ }^{1}$, S. Fujioka ${ }^{2}$, Z. Zhang ${ }^{2}$, H. Nishimura ${ }^{2}$, K. B. \\ Fournier $^{1}$
}

\author{
${ }^{1}$ Lawrence Livermore National Laboratory, 7000 East Avenue, Livermore, California 94550, USA \\ ${ }^{2}$ Institute of Laser Engineering, Osaka University, 2-6 Yamada-Oka, Suita, Osaka 565-0871, Japan
}

Creating intense multi-keV $\mathrm{x}$-ray sources is of great importance for several applications such as radiography of Inertial Confinement Fusion (ICF) plasma experiments and ablation studies. The objective here is to create nanosecond-long sources that are as bright as possible. Laser-heated targets of several types have been studied in the past; they contain mid-Z elements such as $\mathrm{Ti}, \mathrm{Fe}$ or Ge to produce K-shell $\mathrm{x}$ rays with energies of a few keV. For instance, metal foils, pre-exploded foils [1], metal-doped aerogels [2], metal oxide nanofibers [3], and gas-filled targets [4] can achieve from 1 to $10 \%$ laser-to-X-ray conversion efficiencies (CE).

A campaign was carried out to test and characterize $\mathrm{x}$-ray sources from laser-irradiated targets composed of titanium-oxide aerogels at very low density $\left(<10 \mathrm{mg} / \mathrm{cm}^{3}\right)$. The goal is to explore the domain between solid metallic foils, with low CE, and gas targets showing high efficiencies due to their low initial density. Previous work shown that aerogels with various dopants (Ti, Fe, Ge, etc.) could be volumetrically heated when the density is in the range 5 to $10 \mathrm{mg} / \mathrm{cm}^{3}$. This very low density is a great challenge for target fabrication, and development of each aerogel is a research project. We present here the first x-ray source experimental results using aerogels, developed from state-of-the-art novel techniques at LLNL, with a high concentration (20 to 33 at. \%) of Ti atoms and a total density between 4 and 8 $\mathrm{mg} / \mathrm{cm}^{3}$. The novel aerogels were of two types. The first type was composed of $\mathrm{TiO}_{2}$ deposited on a $\mathrm{SiO}_{2}$ template, reaching $\sim 20$ atomic $\%$ of $\mathrm{Ti}$. The second type was a pure $\mathrm{TiO}_{2}$ foam, thus having 33 at.\% of Ti. All aerogels were held in a $50 \mu \mathrm{m}$-wall polyimide tube (see Fig. 1).
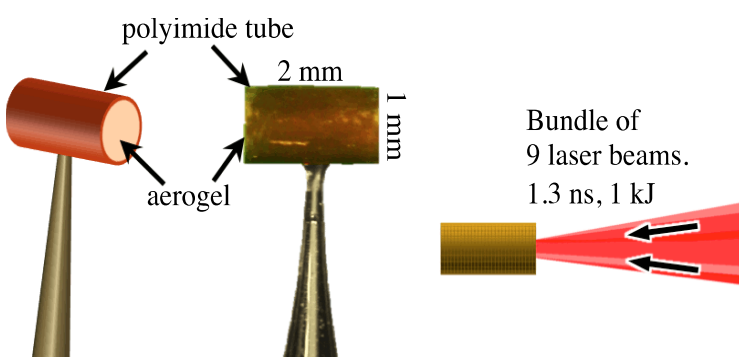

Fig. 1. Target and laser configuration.
Nine beams of the Gekko XII laser were bundled to irradiate one face of cylindrical targets containing aerogel, as shown in Fig. 1. A full set of diagnostics from ILE characterized the multi-keV $\mathrm{x}$-ray yield and the ionization wave propagation as the laser light passes through the aerogel.
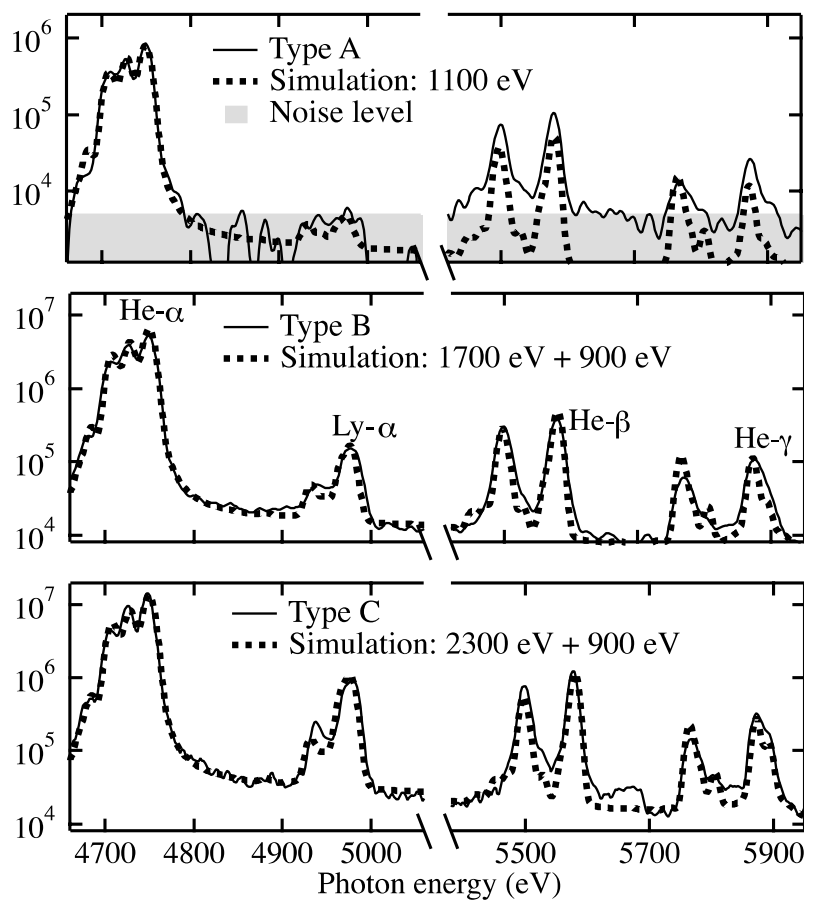

Fig. 2. Experimental $\mathrm{x}$-ray spectra for three different aerogel types. (A) 4\% Ti concentration; (B) $20 \% \mathrm{Ti}$ concentration; (C) 33\% Ti. All three types have a density between 3.7 and $5 \mathrm{mg} / \mathrm{cm}^{3}$.

The $\mathrm{x}$-ray emission of interest was recorded with a high-resolution $x$-ray spectrometer in the range from 4 to $6 \mathrm{keV}$, around the K-shell lines of Ti. Example spectra are plotted in Fig. 2 in solid black lines. By comparing the total yield of the novel aerogels (high $\mathrm{Ti}$ concentration of 20 to $33 \%$ ) to standard aerogels (Ti concentration of $4 \%$ ), the novel type was found to emit 6 to 17 times more $\mathrm{x}$ rays. Knowing that the standard aerogels usually reach a laser-to-x-ray conversion efficiency of $1 \%$, this could translate into a $\mathrm{CE}$ higher 
than $10 \%$ for the novel aerogels. Future campaigns will be dedicated to studying this improvement of $\mathrm{CE}$ in absolute terms.

This great improvement was found to correspond to a significant temperature increase from 1.2 to $2 \mathrm{keV}$ in the heated material. The temperature was inferred from the recorded spectra by matching the line ratios with simulation results from the code SCRAM [5]. This is shown in Fig. 2 with dotted black lines. Such a change of plasma temperature would be expected when the aerogel density is varied, but the present results show that the $\mathrm{Ti}$ concentration is responsible for this change. This new effect will be investigated with atomic kinetics and hydrodynamic simulations.

As shown in Fig. 3, the x-ray emission was also recorded as a function of time using a streak camera [6]. The vertical coordinate is the longitudinal distance along the cylinder central axis ( 0 is the irradiated face). The horizontal coordinate is time. Early in time, the x-ray emission is concentrated near the irradiated face of the target, and at later times, it is emitted deeper in the target. This propagation inside the aerogel material indicates how fast the heat transport and laser penetration occur. Very interestingly, this campaign shows for the first time that the corresponding velocity is lower for a higher $\mathrm{Ti}$ concentration in the aerogel.

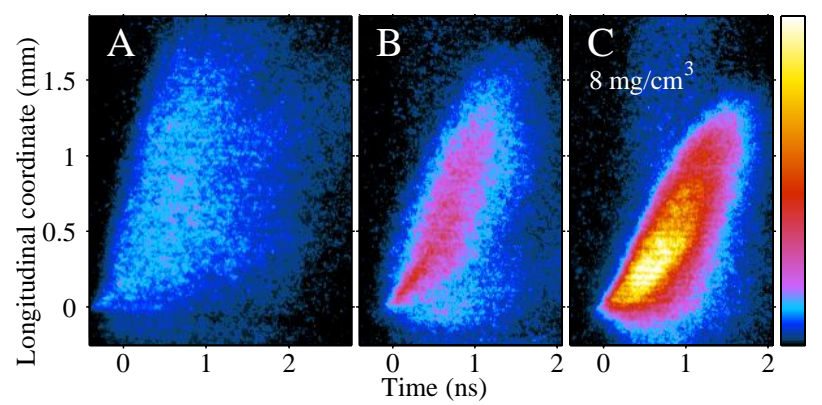

Fig. 3. X-ray emission measured by the streak camera for different Ti concentrations (4\%, 20\%, 33\% respectively). A\&B have a $4 \mathrm{mg} / \mathrm{cm}^{3}$ aerogel density.

Overall, the new aerogel targets tested in this campaign, featuring a high concentration of $\mathrm{Ti}$ atoms, were found to be efficient sources of $\mathrm{K}$-shell $\mathrm{x}$ rays. In addition, the corresponding heating dynamics of the plasma were recorded, and show strong correlation with the $\mathrm{Ti}$ concentration. These results will be interpreted using atomic kinetics and hydrodynamic simulations and will help design better $\mathrm{x}$-ray sources.

\section{ACKNOWLEDGMENTS}

The experimental team at the GEKKO XII facility is gratefully acknowledged for its full support during the experimental campaign. This work was done under the auspices of the (U.S.) Department of Energy by Lawrence Livermore National Laboratory under Contract No. DE-AC52-07NA27344.

\section{REFERENCES}

[1] F Girard et al. Phys. Plasmas 12, 092705 (2005)

[2] K B Fournier et al. Phys. Rev. Lett. 92, 165005 (2004); F Pérez et al., Phys. Plasmas 19, 083101 (2012)

[3] M Tanabe et al., Appl. Phys. Lett. 93, 051505 (2008)

[4] K B Fournier et al., Phys. Plasmas 17, 082701 (2010)

[5] S B Hansen et al., High Energy Density Phys. 3, 109 (2007)

[6] M Tanabe et al., J. of Physics: Conf. Series 112, 022076 (2008) 